ISSN 1518-3483

Licenciado sob uma Licença Creative Commons

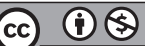

\title{
Matemática moderna nas salas de aula: protagonismos de professores
}

\author{
Modern Mathematics in the classrooms: \\ teachers' protagonisms
}

\begin{abstract}
Elisabete Zardo Búrigo ${ }^{1}$
Professora da Universidade Federal do Rio Grande do Sul (UFRGS), Porto Alegre, RS, Brasil, e-mail: elisabete.burigo@ufrgs.br
\end{abstract}

\section{Resumo}

O trabalho tem como foco a experimentação realizada em salas de aula como preparação da reforma do ensino de Matemática para o primeiro ciclo do segundo grau na França, no fim dos anos 1960. A partir da análise de documentação do período e de trabalhos de autores que investigaram aquela reforma, são discutidas as interveniências de diferentes atores e sua participação na configuração do processo de experimentação. Numa perspectiva comparativa, são propostas algumas reflexões sobre experimentações propostas e conduzidas no Brasil no mesmo período. Busca-se contribuir para a discussão dos diferentes lugares que as práticas de sala de aula podem ocupar nos processos de reformas curriculares.

Palavras-chave: Currículo. História das disciplinas escolares. Educação matemática.

${ }^{1}$ Bolsista Capes Proc. 4194/10-1. 


\section{Abstract}

This study focused on the experimentation carried out in classrooms to prepare for the reform of the teaching of Mathematics of the first cycle of the secondary school in France at the end of the 1960s. Based on the analysis of documents of that period and on the work of authors that investigated that reform, the interference of different actors and their participation in the setup of the experimentation process is discussed. From a comparative perspective, some ideas on the experimentation proposed and performed in Brazil during the same period are proposed with the aim of contributing for the discussion on the different spaces classroom practices may occupy in curriculum reform processes.

Keywords: History of school subjects. Curriculum. Mathematical education.

\section{Introdução}

Nos estudos dos processos de renovação curricular, os professores que atuam nas escolas são frequentemente considerados como segunda ou terceira instância de configuração dos currículos. Os programas teriam sido projetados por especialistas, decididos pelos legisladores ou administradores, e seriam, então, no momento da implementação, interpretados, modificados, rejeitados ou simplesmente ignorados pelos professores. Um tema recorrente, nessas análises, é o da "resistência às mudanças" por parte dos professores. São menos estudados os casos em que grupos de professores atuando em sala de aula provocaram, anteciparam, ou de algum modo, incidiram sobre as proposições de inovações.

No processo que ficou conhecido como Matemática Moderna, e que ocorreu, segundo Matos e Valente (2010, p. 3), "um pouco por todo o mundo" a partir da segunda metade dos anos 1950, podem ser identificadas outras trajetórias que não a do planejamento centralizado e posteriormente aplicado nas escolas. Os autores observam que, em alguns países, as iniciativas de professores precederam a incorporação oficializada das mudanças. 
Outras possibilidades de dinâmicas foram instauradas pelas experimentações - incentivadas por diferentes agentes - em salas de aula, de novos programas e novos métodos. Na França, uma reforma do ensino de matemática, conduzida oficialmente no fim dos anos 1960, foi precedida e acompanhada de uma iniciativa organizada de experimentação que abarcou algumas dezenas de turmas das quatro séries do primeiro ciclo do segundo grau ${ }^{2}$. No Brasil, as experimentações inspiradas na Matemática moderna, ao longo dos anos 1960 e 1970, resultaram da iniciativa de professores ou grupos regionais engajados no movimento ${ }^{3}$.

A experimentação francesa produziu uma farta documentação. Neste trabalho, a partir da análise de documentos daquele período, e tomando como referência a análise da reforma por outros autores, especialmente D'Enfert e Gispert (2010), procuramos construir um esboço da dinâmica dessa experimentação, destacando as ações dos experimentadores e procurando identificar o sentido a elas atribuído pelos diferentes atores que intervieram no processo. A partir dessa discussão, enunciamos alguns caminhos para investigação das experiências desenvolvidas no Brasil e do sentido a elas atribuído pelos professores envolvidos.

Buscamos, com este trabalho, contribuir para os estudos comparativos que vêm se desenvolvendo no âmbito da história da educação matemática e, também, para a discussão de diferentes possibilidades de dinâmicas de reconfigurações curricular onde as práticas da sala de aula ocupam um lugar que não se circunscreve à "última" etapa do processo de mudança.

\section{Antecipando e preparando a reforma}

Já desde os anos 1950, segundo D’Enfert (2010), um grupo de professores franceses do ensino secundário, articulado no âmbito da

2 O primeiro ciclo do segundo grau inclui as séries sixième (11 a 12 anos), cinquième (12 a 13), quatrième (13 a 14), troisième (14 a 15 anos) e é oferecido em instituições denominadas, desde os anos 1960, collèges. ${ }^{3}$ Vários trabalhos que mencionam as experimentações estão citados em Búrigo, Oliveira Filho e Rios (2010). 
Association des Professeurs des Mathématiques de l'Enseignement Public $(\mathrm{APMEP})^{4}$, e em contato com a Comissão Internacional pelo Estudo e Melhoria do Ensino de Matemática (CIEAEM), produzia textos que propunham a renovação dos conteúdos e dos métodos de ensino de matemática. Segundo o autor, antecipando-se às reformas anunciadas para o ensino secundário, os professores da APMEP percebiam nessa provável reestruturação a possibilidade de valorização do ensino de matemática e de ampliação da sua carga horária. Suas proposições de renovação de conteúdos e métodos de ensino estavam vinculadas, então, a um movimento de afirmação da disciplina no âmbito do currículo escolar. As cargas horárias seriam de fato ampliadas em 1957, mas os programas de matemática do primeiro ciclo do secundário não foram impactados pelas reformas Berthoin (1959) e Fouchet $(1963)^{5}$, sofrendo pequenas alterações até a primeira metade dos anos 1960, permanecendo como referência os conteúdos ensinados até então nos liceus, passíveis de interpretação segundo as finalidades atribuídas às diferentes modalidades.

A perspectiva de uma reforma do ensino de Matemática, contudo, permaneceu no horizonte dos professores que atuavam na APMEP, e o tema ocupou, ao longo dos anos 1960, um espaço crescente no debate interno e nas iniciativas da Associação.

A conjuntura internacional era favorável à modernização: organismos de peso como a Organização para a Cooperação e o Desenvolvimento Econômico (OCDE) e a Unesco incentivavam as reformas e divulgavam experiências de países vizinhos como Bélgica e Alemanha (ICMI, 1966). Além disso, na França, os programas de Matemática do segundo ciclo do secundário sofreram várias modificações, sobretudo a partir da reforma de junho de 1965, que reorganizou suas ênfases ou terminalidades.

\footnotetext{
${ }^{4}$ Associação de Professores de Matemática do Ensino Público (nossa tradução).

${ }^{5}$ As reformas Berthoin e Fouchet, assim como a dinâmica geral da reforma do ensino de matemática na França, estão bem explicados na versão traduzida do artigo de D'Enfert e Gispert (2010), publicada neste mesmo número da Revista. O Comitê era a principal instância diretiva da APMEP; seus membros eram eleitos por voto direto dos sócios.
} 
Os professores da APMEP criticavam a "improvisação e a desordem" com que a reforma do segundo ciclo era implementada, e o segredo em que eram formulados os projetos oficiais, conhecidos das editoras de livros didáticos antes de sua divulgação entre os professores (WALUSINSKI, 1966, p. 144-145). Mas longe de se opor às mudanças, tomavam esse "começo" de reforma como mais uma motivação para a proposição e preparação de uma renovação ampla, profunda e articulada do ensino de matemática, "da pré-escola à faculdade".

De um lado, a reforma se constituía numa bandeira e era encarada mesmo como uma tarefa da APMEP. Assim, a assembleia geral da APMEP reunida em 2 de maio de 1965 conferiu mandato a uma comissão ampla para apresentar, na assembleia geral do próximo ano, "um plano completo de reforma do ensino de matemática” (APMEP, 1965, p. 499). O mandato à comissão foi reiterado na assembleia reunida em maio de 1966, e na sequência o Comitê da $\mathrm{APMEP}^{6}$ aprovou uma moção solicitando ao Ministério da Educação Nacional "a constituição de uma Comissão especial reunindo administradores e professores de todos os níveis”, com o objetivo de elaborar os novos programas (APMEP, 1966a, p. 495).

Ao mesmo tempo, a APMEP formulava um leque de reivindicações que eram apresentadas como condições para que ocorresse uma "verdadeira reforma”. O leque era amplo e incluía temas variados: ampliação do efetivo de professores e das vagas oferecidas nos concursos, melhoria da remuneração dos professores, ampliação da carga horária de matemática, melhoria das condições materiais de ensino nas escolas e limitação do número de alunos em sala de aula. A preparação para a reforma envolvia, também, a proposição de prazos alargados entre a divulgação e a implementação dos novos programas. Na proposta encaminhada ao ministério em maio de 1966, previa-se a divulgação dos novos programas até janeiro de 1968, para implementação progressiva a partir de setembro de 1970, isto é, com um intervalo de dois anos e meio (APMEP, 1966a).

${ }^{6}$ O Comitê era a principal instância diretiva da APMEP; seus membros eram eleitos por voto direto dos sócios. 
Um elemento central do discurso da APMEP era o da importância atribuída à formação continuada para os professores. A associação desenvolvia suas próprias iniciativas de formação e debate: conferências realizadas em cooperação com a Societé Mathématique de France ${ }^{7}$, desde os anos 1950; cursos sobre tópicos de Matemática como Álgebra e Topologia; jornadas anuais de estudo envolvendo a discussão de temas variados. $\mathrm{Na}$ segunda metade dos anos 1960, ganhou destaque nos debates da APMEP a reivindicação do investimento governamental na formação continuada de professores associada à pesquisa sobre o ensino. Em defesa desse pleito, eram citadas as recomendações da OCDE e da Unesco relativas à reciclagem de professores. Na assembleia geral da APMEP de maio de 1965, foi aprovada a proposta de criação de um Centre de Liaison, d'Action, d'Information et de Recherche sur L'Enseignement des Mathématiques (Clairem) ${ }^{8}$. Em maio de 1966, foi aprovada a proposta de constituição de um Institut de Recherche sur l'Enseignement des Mathématiques (IREM) ${ }^{9}$ em cada circunscrição administrativa do Ministério da Educação (APMEP, 1966b).

\section{A experimentação no desencadeamento da reforma}

A reforma dos programas de Matemática do ensino de segundo grau foi finalmente anunciada em outubro de 1966 pelo Ministro da Educação Nacional. Uma Comissão de Estudos sobre o Ensino de Matemática, que ficou conhecida como Comissão Lichnerowicz, ficaria incumbida de redigir os novos programas (D’ENFERT; GISPERT, 2010).

Contando com a presença de professores universitários, secundários e inspetores gerais da área de matemática, a Comissão Ministerial tinha, desde o início dos seus trabalhos, vários de seus membros vin-

\footnotetext{
7 Sociedade Matemática da França (nossa tradução).

${ }^{8}$ Centro de Ligação, de Ação, de Informação e de Pesquisa sobre o Ensino da Matemática (nossa tradução).

9 Instituto de Pesquisa sobre o Ensino de Matemática (nossa tradução).
} 
culados à APMEP. A associação, por sua vez, preparou-se para intervir na Comissão Ministerial, reunindo sua própria comissão redenominada, em maio daquele ano, "Comission Recherche et Réforme"10. Em janeiro de 1967, essa comissão aprovou um relatório contendo proposições detalhadas sobre a formação continuada dos professores e sobre a experimentação pedagógica, considerada "indispensável antes da aplicação generalizada de um novo programa” (WALUSINSKI, 1967).

A organização da Comissão Ministerial, desde o início, indicava que seu temário iria além da formulação de novos programas: entre as quatro subcomissões criadas, uma estava voltada para a "formação continuada e experimentação". Essa subcomissão era coordenada por André Revuz - matemático, professor da Faculdade de Ciências de Poitiers e membro ativo da APMEP ${ }^{11}$ (COMISSION, 1967a).

O Relatório Preliminar da Comissão Ministerial, publicado em março de 1967, anunciava um amplo e continuado processo de reforma de programas e métodos do ensino de matemática, que não se esgotaria com a implementação dos novos programas. Uma das proposições apresentadas no relatório era a da criação dos IREM que, vinculados às universidades, teriam a dupla tarefa de assegurar a formação continuada dos professores e de "organizar as experiências desejáveis sobre o ensino de matemática, a fim de se poder passar das conclusões eventuais para os fatos, de maneira mais ou menos progressiva" (COMISSION, 1967b, p. 257). As experiências das quais os IREM estariam incumbidos inscreviam-se, portanto, num programa continuado de pesquisas relacionadas ao ensino.

Ao mesmo tempo, o relatório indicava que era necessário explorar, "a partir de experiências, novos métodos de ensino relativos aos vários graus [de ensino]" e também "experimentar, antes de sua adoção, certos projetos de programa” (COMISSION, 1967b, p. 249, itálico no

10 Comissão "Pesquisa e Reforma" (nossa tradução).

${ }^{11}$ Revuz era vice-presidente da APMEP e havia sido Presidente da entidade entre 1960 e 1962 . Nesse período, também proferiu cursos e conferências para os professores da APMEP, depois publicados como livros. 
original). Segundo essa lógica, o calendário desenhado pela comissão previa: a realização de experimentações envolvendo a aplicação dos novos programas para a classe sixième (nos anos letivos de 67/68 e 68/69) e para a classe cinquième (nos anos letivos de 68/69 e 69/70)12; a correção dos programas, antes de sua "generalização", respectivamente, em setembro de 1969 e em setembro de 1970. O relatório recomendava que os professores engajados em experiências organizadas ou em atividades de autoaperfeiçoamento fossem "remunerados pelo tempo suplementar consagrado a essas atividades e que os custos eventuais de deslocamento fossem assumidos [pelo Ministério]" (COMISSION, 1967b, p. 249, grifo do autor).

Pode-se identificar, na dinâmica inicial da Comissão Ministerial e nesse conjunto de recomendações - que não se limitavam ao enunciado de princípios gerais, mas indicavam um conjunto de medidas práticas a serem encaminhadas pelo ministério - a marca da participação organizada e da influência dos professores da APMEP.

Num balanço publicado quase 20 anos depois, Gilbert Walusinski (1986), uma das principais lideranças da APMEP nos anos 1960, sugere que o relatório, reproduzido à época no Bulletin de l'APMEP ${ }^{13}$, teria sido ignorado pelo Ministério da Educação. Mas não de todo:

[...] nada foi traduzido para a realidade do ensino. Nada ou quase nada. Esse 'quase' não é neglicenciável: a CL [Comissão Lichnerowicz] havia preconizado a organização de classes experimentais para o estudo dos novos programas, começando pelos da sixième. Milagre, isso foi feito. Equipes de dois ou três colegas nos estabelecimentos, distribuídos em várias regiões, beneficiaram-se de estágios preparatórios e, depois, de estágios de verificações necessárias. Tal trabalho conduziu, tal como estava previsto, a uma pesquisa didática prática [...] (WALUSINSKI, 1986, tradução nossa).

12 Para a designação das séries do ensino secundário francês, ver segunda nota de rodapé, neste artigo.

${ }^{13}$ Boletim da APMEP, órgão de divulgação da entidade, de periodicidade trimestral. 


\section{O primeiro ano da experimentação planejada}

No ano letivo de 1967-1968, a experimentação envolveu, segundo relato de André Revuz, em torno de 50 classes de sixième. A organização da experiência foi atribuída pelo ministério ao Institut Pédagogique National (IPN) ${ }^{14}$. Tratava-se de uma experimentação planejada e avaliada por meio de um processo em que se articulavam várias instâncias: equipes de estabelecimento reuniam-se semanalmente, equipes regionais pelo menos mensalmente e estágios nacionais trimestrais garantiam a troca de informações e a discussão dos resultados num âmbito mais amplo (REVUZ, 1969, p. 5).

Os programas de referência para o trabalho das classes experimentais haviam sido apresentados em anexo ao Relatório Preliminar da Comissão Ministerial. O programa proposto para a sixième incluía quatro unidades, envolvendo o estudo de medidas de grandezas físicas, uma introdução às relações e funções, o estudo das operações com números naturais e decimais e uma introdução aos números relativos (inteiros e decimais). No âmbito dos conteúdos, a principal inovação em relação ao programa vigente era o estudo das relações e funções, envolvendo a introdução do "vocabulário dos conjuntos"; mas também eram novidades o estudo, nessa série, dos mecanismos e das "significações" das operações e a introdução aos relativos. Em contrapartida, eliminavam-se do programa várias definições de polígonos e sólidos e fórmulas de cálculo de volumes como o da esfera, pirâmide e cone. Uma nota preliminar indicava ainda que a ordem das rubricas do programa não era imperativa, sendo "mesmo recomendado estender, ao longo do ano letivo, cada uma das três primeiras rubricas" (COMISSION, 1967b, p. 270-271). O horário das turmas experimentais foi ampliado em uma hora semanal, na qual estava prevista a repartição de cada turma em dois grupos.

Revuz (1969) sublinha que os professores engajados na experiência não dispunham de nenhum manual ou livro didático a ser tomado

${ }^{14}$ Instituto Pedagógico Nacional (nossa tradução). 
como referência. O principal recurso utilizado na maioria das regiões eram "fichas de trabalho" elaboradas e avaliadas pelas próprias equipes regionais. Segundo o autor, a opção pelas fichas era orientada pelo desejo de promover um ensino ativo, encorajando a iniciativa e a reflexão pessoal dos alunos. As fichas organizavam o estudo progressivo dos temas apresentando textos e exercícios simples, a serem percorridos numa sequência fixa, mas segundo o ritmo de cada aluno ou pequeno grupo. Os relatos esclarecem que as dinâmicas de trabalho variavam segundo as regiões: em Sèvres, o uso das fichas era alternado com momentos de "discussões orais", para introdução de algumas noções, discussão de um exercício ou construção coletiva da síntese do trabalho desenvolvido; em Lyon, o papel atribuído ao professor era o de circular entre as classes, auxiliando os alunos na resolução de alguma dificuldade, provocando-os à reflexão, sendo mais eventuais as discussões em grande grupo ou o uso do quadro-negro (BRAILLY; DUVERT; FORT, 1969).

Quanto ao programa adotado, é interessante observar que, havendo flexibilidade quanto à ordem dos conteúdos a serem trabalhados, todas as equipes optaram por iniciar o ano letivo com conteúdos novos: em Lyon, conjuntos, relações e funções, composições de bijeções e codificações; em Sucy e Sèvres, conjuntos, orientação/localização, relações e contagem; em Saint-Germain, codificação e decodificação, conjuntos e contagem; em Toulon, Marseilleveyre, Poitiers e Couhé-Vérac, relações e conjuntos.

A experimentação de maior porte ocorreu em Lyon, envolvendo cerca de 40 turmas. As fichas produzidas em Lyon, discutidas por todos os "voluntários da equipe completa" e redigidas por uma equipe mais reduzida, foram publicadas em setembro de 1968, com modificações, sob o título Mathématiques en sixième, sob a autoria de E. Galion, pseudônimo para a equipe. As modificações refletiam já a experiência desenvolvida nas turmas: por exemplo, a noção de relação não constituiu um capítulo, mas foi utilizada como ferramenta nas situações em que isso fazia sentido (GLAYMANN, 1969).

A autoria dos professores envolvidos na experimentação não se esgotava, portanto, na produção dos materiais utilizados em sala de aula. 
Envolvia a avaliação desses materiais, a partir da sua implementação, das reações dos alunos, das aprendizagens ou dificuldades evidenciadas, dos diálogos em sala de aula, das questões ou reflexões suscitadas.

Assim, por exemplo, em um artigo que tem como subtítulo Exemplo de fichas e de crítica das fichas, uma professora reflete sobre uma atividade desenvolvida em sala de aula, onde os alunos eram solicitados a avaliar a área de uma região poligonal utilizando quadriculados cada vez mais finos (ao invés de aplicar uma fórmula):

Os exercícios sobre o enquadramento de medidas revelaram aos alunos de $6^{\mathrm{e}}$ que a medida de um ente físico só pode ser definida com uma certa incerteza. Um deles até mesmo disse: "Mas então, tudo que nos ensinaram na escola primária era falso!"

Nós tínhamos desejado essa tomada de consciência, nós a consideramos como um dos resultados positivos do nosso novo ensino. Mas nós nos perguntamos se o despertar do espírito crítico nos alunos que ainda não têm nenhuma noção do que distingue a realidade física da verdade matemática não corre o risco de degenerar em ceticismo generalizado:

- para nossos alunos de 6e, a área de um retângulo é igual ao produto das medidas dos lados ou é aproximadamente isso, com uma diferença menor do que 1 milímetro quadrado? (FORT ET DEHAME, 1969, p. 55, nossa tradução).

\section{Uma nova conjuntura em 1968}

No segundo semestre de 1967, por interveniência do ministério, os trabalhos da Comissão Ministerial foram interrompidos, suscitando dúvidas sobre o andamento do processo já deflagrado. Mas a APMEP se mantinha organizada e mobilizada para intervir em favor da e na preparação da reforma. Em janeiro de 1968, a APMEP promoveu um colóquio em Chambèry, que produziu um documento afirmando a necessidade e a viabilidade de uma ampla reforma do ensino de matemática e detalhando as condições necessárias para o seu sucesso. Em abril de 1968, a versão 
definitiva do documento, denominado Charte de Chambèry, foi aprovada em assembleia geral da APMEP. O documento reivindicava uma "genuína" experimentação:

[...] as escolas que realizam a experiência devem contar com condições favoráveis, o número de efetivos de cada turma não podendo exceder 24 alunos. A experimentação deve ser feita em meios socioculturais diversos. É recomendável nesse ocasião colocar-se em questão a mitologia das notas, das composições, das classificações, dos exames... A experimentação em seus diversos níveis deve ser coordenada. [...] Enfim, para que possa servir a todos os professores, as escolas experimentais devem ser facilmente visitadas; os resultados das pesquisas devem ser publicados e colocados à disposição de todos (APMEP, 1968a, p. 5).

Vê-se, aí no documento, algumas das intenções que moviam os militantes da APMEP na defesa da experimentação.

Em primeiro lugar, a experimentação é tratada como um momento de verificação e de conquista das condições necessárias para que se realize um ensino renovado. A limitação do número de alunos em 24 é uma reivindicação que não se cinge às turmas experimentais: a experimentação é um momento oportuno para a reivindicação de condições para que se promovam os métodos ativos de aprendizagem.

Em segundo lugar, a experimentação também se configura em oportunidade de colocar em suspenso um conjunto de regramentos que engessam a ação dos professores; entre eles, a fiscalização do cumprimento dos programas oficiais pela Inspeção Geral de Matemática.

Em terceiro lugar, reivindica-se não só a publicização das reflexões e dos resultados das experimentações - que até então não tinha sido organizada -, mas que os professores pudessem visitar as escolas, isto é, que pudessem compreender as condições em que as experimentações foram realizadas, conversar com colegas e alunos, construir suas próprias apropriações das experimentações realizadas.

Portanto, a experimentação, no discurso da APMEP, não tinha o sentido de uma mera validação dos programas a partir da obtenção de 
resultados positivos nas turmas envolvidas. Entre outros aspectos, a experimentação atribuía à sala de aula e aos professores que ali atuavam um lugar de destaque na discussão sobre a reforma.

A Charte de Chambèry também dava destaque à reivindicação de criação imediata dos IREM, como instituições incumbidas da articulação entre a pesquisa, a experimentação e a formação permanente dos professores.

As ações da APMEP seriam favorecidas pelos eventos de maio de 1968 que, segundo Prost (2004), modificaram as condições e os termos do debate sobre o ensino secundário e universitário na França, colocando em questão tradições, hierarquias, títulos e distinções de percurso escolar. Reunido em 12 de maio de 1968, dois dias depois de conflagradas manifestações no entorno da Sorbonne, em Paris, o Comitê da APMEP aprovou uma moção de solidariedade aos estudantes:

A ausência de qualquer diálogo entre os poderes públicos e a Universidade (professores e estudantes) explica em grande parte a situação atual. Uma associação de especialistas como a APMEP tem, essencialmente, preocupações de ordem pedagógica que impõem o dever, face à gravidade dos eventos, de afirmar sua solidariedade com o movimento estudantil em sua luta pela renovação e democratização da Educação Nacional (APMEP, 1968b, p. 382, nossa tradução).

Ao longo do mês de maio, o movimento prolongou-se, estendeu-se aos liceus, envolvendo professores e estudantes do secundário, e repercutiu em greve geral com ocupações de fábrica, abalando a estabilidade do governo francês (PROST, 2004).

Em 9 de junho, o Comitê da APMEP reuniu-se e aprovou um documento onde, de um lado, apoiava consignas de contestação a regramentos vigentes - como os mecanismos de inspeção da ação dos professores e de avaliação e classificação dos alunos - e, de outro lado, insistia no tema da valorização da Matemática no currículo escolar, mencionando a importância da "cultura científica no mundo moderno" e o direito de cada cidadão a uma "formação matemática renovada que lhe permita fazer um 
uso racional e crítico das técnicas" (APMEP, 1968c, p. 386-387). Assim, ao mesmo tempo em que marcava sua identidade com o movimento de maio, a APMEP buscava ocupar, com seus próprios temas, o espaço aberto para o questionamento e o debate.

Nesse contexto, e com a nomeação de um novo ministro da educação, Edgar Faure, foi conquistada a criação de três IREMs em 1968: Paris, Lyon e Strasbourg. Revuz e Glaymann, ex-presidentes e membros ativos da APMEP, foram nomeados respectivamente diretores dos IREM de Paris e de Lyon. A principal tarefa atribuída aos IREM, nesse período, seria a da preparação dos professores para a implementação da reforma.

\section{A implementação da reforma}

Em setembro de 1969, afinal, teve início a implementação da reforma. Os novos programas, concebidos pela Comissão Lichnerowicz e oficializados por portaria de julho de 1968, deviam ser adotados por todas as turmas de sixiéme ${ }^{15}$.

O Bulletin de l'APMEP comemorava a deflagração da reforma. Ao mesmo tempo, publicava vários relatos de experimentações realizadas no ano letivo de 1968-69, abrangendo turmas de sixième e de cinquième. Os dirigentes da APMEP assinalavam, desse modo, a importância atribuída à experimentação, vinculada a uma concepção de reforma:

Esse é um começo [...] que deflagra um processo de reforma permanente [...]. É por isso que nós, que temos que traduzir esses princípios em fatos, temos menos necessidade de textos oficiais do tipo "programas" ou mesmo "instruções" do que de testemunhos diretos, de trocas entre nós para confrontarmos nossas tentativas, dar ao trabalho de equipe todo seu valor, formando equipes de equipes. [...] eu sei com que aplicação e preocupação em ajudar os professores esses textos [oficiais] foram

${ }^{15}$ Os programas referiam-se às modalidades I e I| de ensino secundário, não atingiam as "classes de transição". 
redigidos. Mas, quaisquer que sejam suas intenções, são textos e generalidades. Nossa ambição, publicando esse número especial, é totalmente outra. Há um ou dois anos, conforme o caso, colegas fizeram experimentações nas suas turmas segundo as perspectivas abertas pelo projeto da reforma. Há aí uma quantidade de realidades vividas. Montaigne disse: 'É sempre agradável ver as coisas escritas por aqueles que tentaram fazer do modo como se deve' (WALUSINSKI, 1969, p. 271).

Os relatos das experimentações, na ótica da APMEP, atestavam não só a viabilidade dos novos programas, mas também das novas metodologias utilizadas. A contraposição entre relatos de experimentações e programas também tinha o sentido de valorizar a iniciativa dos professores e assinalar os limites da prescrição curricular construída fora da sala de aula.

Essa prescrição, de fato, não era construída apenas por meio dos programas, mas também por meio dos livros didáticos, que agora chegavam às escolas. Os experimentadores registravam a crítica aos novos livros e à sua interpretação dos programas:

Os novos livros da sixième começam a chegar, mais grossos que os precedentes, aparentemente. Seu conteúdo ultrapassa consideravelmente aquilo que poderíamos ter feito em um ano (GROUPES DE BOURDEAUX ET TALENCE, 1970, p. 8).

Em setembro de 1969 também tinha início a experimentação nas classes de quatrième. Os programas experimentais construídos pela Comissão Ministerial, que tratavam da construção dos números reais e da Geometria plana segundo uma abordagem axiomático-dedutiva, haviam sido questionados pelos experimentadores nos estágios coordenados pelo IPN em maio e setembro. Segundo Colomb e Dumont (1969, p. 679), foi elaborado "às pressas" um novo programa, chamado "projeto Revuz". Segundo o próprio Revuz (1972), então diretor do IREM de Paris, foi "o trabalho minucioso dos experimentadores que mostrou a possibilidade" da abordagem - inovadora - dos números reais a partir dos cálculos aproximados com os decimais, incorporada depois no programa oficial (REVUZ, 1972, p. 6). 
Já a abordagem proposta para a Geometria seguiu sendo objeto de contestação. Em junho de 1970, já no fim do primeiro ano de experimentação com as classes de quatrième, os experimentadores, reunidos em Orléans em estágio nacional, aprovaram um documento dirigido à Comissão Ministerial, onde relatavam dificuldades com o cumprimento do programa e com o tratamento dedutivo proposto para a Geometria, desde o início. Nesse documento, reivindicavam que: os programas da quatriéme e da troisième não comportassem uma "teoria dedutiva completa da Geometria"; cada professor pudesse optar por "ilhas dedutivas" de sua própria escolha, "sem referência a uma axiomática única imposta pelo programa"; os programas fossem flexíveis, com objetivos modestos e bem delimitados. Ao mesmo tempo em que reivindicavam a revisão do programa, algumas equipes apresentavam propostas alternativas ancoradas em suas próprias experiências (APMEP, 1970, p. 444-445).

Essa discussão sobre os programas para a Geometria não foi abordada na publicação do IPN dedicada à experimentação para a quatrième, que tratou apenas dos números reais. A APMEP, por sua vez, divulgou a carta dos experimentadores e as propostas alternativas de programa para a Geometria, inclusive uma formulada por um grupo de experimentadores do IPN (APMEP, 1970). Em audiência com Lichnerowicz, a direção da APMEP reivindicou "liberdade de ação" em relação à Geometria. A disposição de rever o programa, entretanto, teria sido obtida apenas após a interveniência de outros interlocutores, professores do ensino superior: "só podemos lamentar o peso [reduzido] das opiniões dos professores mesmos da quatrième junto à Comissão Lichnerowicz" (BELOUZE, 1971, p. 104).

O debate sobre os programas da quatrième estendeu-se e ampliou-se com a interveniência de outros interlocutores, alcançando a dimensão de uma crise apenas parcialmente superada com a aprovação de novo texto em fevereiro, publicado oficialmente em julho de 1971 (D'ENFERT; GISPERT, 2010).

Em junho de 1971, a APMEP publicava um amplo leque de artigos e relatos sobre as experimentações na quatrième, envolvendo 
diferentes abordagens e adaptações do programa. E marcava seu apoio à continuidade das experimentações:

É a existência de uma ampla experimentação que permitiu que os artigos de fundo fossem complementados e esclarecidos por artigos mais pedagógicos e mais próximos das realidades do ensino. Isso prova que uma reforma não pode ser empreendida e prosseguida com legitimidade se ela não for precedida e acompanhada de uma experimentação; ora, a administração da Educação Nacional parece querer frear, e até mesmo interromper a experiência pedagógica em Matemática (BUISSON, 1971, p. 254, nossa tradução).

\section{A conclusão da experimentação}

Em setembro de 1971, teve início a aplicação generalizada do novo programa para a quatrième. Em novembro, foram organizadas pela administração, em conjunto com o INRDP ${ }^{16}$, "jornadas de informação" para os professores dessas turmas. A APMEP, além de criticar a brevidade e o caráter meramente informativo das atividades, mais uma vez marcava seu desacordo com o papel secundário atribuído aos experimentadores, que corresponderiam a uma proporção "insignificante" dos animadores das jornadas (COLMEZ, 1972, p. 170).

A experimentação oficialmente conduzida se encerrava em 1972, quando a segunda vaga de turmas experimentais chegava ao fim da troisiéme. Em 1971, a APMEP havia proposto, sem obter acordo do ministério, uma nova vaga de experimentações.

O balanço da experimentação não era consensual entre o INRDP e os IREM - que já eram 13 ao fim de 1971 -, que partilhavam a coordenação das experimentações. Enquanto o diretor do IREM de Paris valorizava "a diversidade das vias de ataque e a autonomia das diversas equipes", cujo trabalho devia ser facilitado, e seus resultados difundidos e utilizados (REVUZ,

${ }^{16}$ Institut National de la Recherche et de la Documentation Pédagogique, antigo IPN. 
1972, p. 7), o diretor de pesquisa do INRDP mencionava o caráter "subjetivo" das apreciações dos experimentadores para distingui-las de uma pesquisa em maior escala e em "situação escolar controlada", a ser encaminhada pelo Instituto (LEGRAND, 1972, p. 8-9).

A adoção de novas metodologias de ensino - e particularmente o trabalho com as "fichas" -, um dos principais aportes da experimentação, também era objeto de conflito. A assembleia geral da APMEP, em maio de 1971, aprovou moção lamentando que "colegas, em particular jovens, tenham sido sancionados por ter utilizado métodos não tradicionais" (APMEP, 1971, p. 630). A assembleia geral de maio de 1972 aprovou duas moções relativas ao tema: a primeira, criticando a rigidez no uso dos recursos para compra de livros didáticos, "frequentemente inadequados e não utilizados", e sugerindo o uso desses recursos para a confecção de fichas elaboradas pelos professores; a segunda, denunciando a "pressão intolerável" sofrida pelos professores quanto à escolha de meios e métodos, e a ação da Inspeção Geral contra as fichas como "atentado à liberdade pedagógica do professor” e à melhoria do ensino (APMEP, 1972, p. 858).

A extensão dos resultados das experimentações às demais classes foi, segundo Revuz (1999, p. 91, nossa tradução), limitada, sobretudo no que se refere ao uso dos métodos ativos:

As classes experimentais satisfaziam tanto os professores quanto os alunos, e tinham o mérito de fornecer teoremas de existência do tipo 'É possível ensinar tal noção a tal público' à condição de se utilizar métodos ativos capazes de provocar a iniciativa dos alunos, e algumas vezes se assistiu à utilização catastrófica de sequências que se haviam mostrado muito eficazes.

\section{Para um estudo das experimentações da Matemática moderna no Brasil}

No caso francês, os experimentadores não assumiram o papel de simplesmente aplicar programas e orientações elaborados em outra instância (Comissão Ministerial ou Inspeção Geral). Estavam engajados 
no processo de modernização: construíram novos materiais, experimentaram diferentes abordagens e, quando avaliaram que o programa da quatrième era inadequado, não se afastaram do processo, mas expressaram seu desacordo e formularam propostas alternativas, procurando incidir sobre a reforma de conjunto. De acordo com os dirigentes da APMEP, as avaliações dos experimentadores não foram considerados pela Comissão Ministerial. Mas encontraram eco na própria associação, que cumpriu um papel importante na reivindicação de flexibilizações dos programas (D'ENFERT; GISPERT, 2010).

De acordo com os próprios experimentadores, suas avaliações também não foram consideradas na produção dos novos livros didáticos, que apresentavam versões dos programas impossíveis de serem cumpridas pelos professores. Por outro lado, a experimentação produziu a vivência compartilhada da prescindibilidade dos livros, que subsistiu ao período da experimentação e se expressou na defesa da continuidade da elaboração e do uso das "fichas de trabalho".

Durante o processo de experimentação, segundo vários depoimentos, a relação de hierarquia entre inspetores e professores das escolas foi substituída por relações mais horizontais entre professores universitários, secundários e inspetores. Em parte, isso pode ser atribuído à suspensão do programa oficial, objeto de fiscalização por parte dos inspetores. Pode ser também atribuído ao contexto mais geral instaurado pelo movimento de maio de 68 . Os conflitos com os inspetores ressurgiriam no decorrer da própria reforma; mas é interessante observar que eles se tornaram objeto de contestação organizada pela APMEP.

A APMEP, ademais, cumpriu um papel decisivo em todo o processo: de um lado, propôs a experimentação como componente da reforma e valorizou o saber construído pelos professores frente ao dos especialistas e tomadores de decisão; ao mesmo tempo, reivindicava melhores condições de trabalho e remuneração para todos os professores de matemática. Essa articulação entre as reivindicações típicas de um sindicato e o engajamento na reforma pode ser considerada como expressão do protagonismo de um amplo grupo de professores. 
No Brasil, não houve um processo amplo e oficializado de experimentação da matemática moderna, como na França. Há, contudo, vários registros de experiências de ensino que envolveram, de um lado, propostas de inovação de conteúdos ou métodos e, de outro, algum tipo de planejamento e de avaliação que, nesse sentido, podem ser consideradas experimentações. Não se tratava de testar programas prescritos oficialmente, e o caráter voluntário do envolvimento faz já supor o engajamento dos professores experimentadores na inovação curricular do ensino de Matemática. Mas as motivações e o caráter desse engajamento estão por ser investigados.

$\mathrm{Na}$ França, os conflitos que envolveram a experimentação foram repercutidos pela APMEP. No Brasil, não houve uma entidade que cumprisse esse papel. O debate educacional e a organização dos professores foram cerceados pela ditadura militar instaurada em 1964. Afora casos como o do Ginásio Vocacional do Brooklyn, em São Paulo, em que a repressão atingiu toda uma experiência de inovação curricular em andamento (RIBEIRO, 1980), estão escassamente documentadas as relações entre experimentadores e autoridades governamentais e outros agentes, como editoras e autores de livros didáticos. O que não pode nos levar a concluir pela inexistência de conflitos ou por um autoisolamento desejado pelos experimentadores. Esperava-se, a partir dos saberes construídos em sala de aula, incidir sobre um processo mais amplo de renovação curricular? Que papel os experimentadores atribuíam a si mesmos? São algumas das questões que merecem ser objeto de novas pesquisas.

\section{Agradecimentos}

A Renaud d'Enfert, pelo apoio na pesquisa e pelas muitas oportunidades de discussão. À Capes, pela bolsa, e ao Serviço de História da Educação do Institut National de Recherche Pédagogique, França, pela acolhida ao estágio em que a pesquisa foi desenvolvida. 


\section{Referências}

Association des Professeurs des Mathématiques de l'Enseignement Public. Assemblé générale 2 mai 1965. Bulletin de l'APMEP, n. 249, p. 497-500, 1965.

Association des Professeurs des Mathématiques de l'Enseignement Public. Comité du 8 mai 1966. Bulletin de l'APMEP, n. 253, p. 493-496, 1966a.

Association des Professeurs des Mathématiques de l'Enseignement Public. Assemblé générale 1966. Bulletin de l'APMEP, n. 253, p. 488-490, 1966b.

Association des Professeurs des Mathématiques de l'Enseignement Public. Charte de Chambéry. Paris: APMEP, 1968a. Disponível em: <http://www.apmep.asso.fr/CHARTE-DE-CHAMBERY-1968>. Acesso em: 25 mai. 2011.

Association des Professeurs des Mathématiques de l'Enseignement Public. Comité du 12 mai 1968. Bulletin de l'APMEP, n. 263-264, p. 382-385, 1968b.

Association des Professeurs des Mathématiques de l'Enseignement Public. Réunion du 9 juin 1968. Bulletin de l'APMEP, n. 263-264, p. 385-387, 1968c.

Association des Professeurs des Mathématiques de l'Enseignement Public. A propos du programme de Quatrième. Bulletin de l'APMEP, n. 275-276, p. 439-455, automne 1970.

Association des Professeurs des Mathématiques de l'Enseignement Public. Assemblé générale 23 mai 1971. Bulletin de l'APMEP, n. 280, p. 625-631, 1971.

Association des Professeurs des Mathématiques de l'Enseignement Public. Assemblé générale 14 mai 1972. Bulletin de l'APMEP, n. 285, p. 857-862, 1972.

BELOUZE, B. A propos du programme de Quatrième. Bulletin de l'APMEP, n. 277, p. 103-104, 1971.

BRAILLY, A.; DUVERT, L.; FORT, J. Techniques d'utilisation des fiches. In: IPN. Mathématiques en 6e: expérimentation et nouveaux programmes. Paris: IPN, 1969. 
BUISSON, P. La réforme dans le premier cycle, deuxième étape. Bulletin de l'APMEP, n. 279, p. 253-254, 1971.

BÚRIGO, E. Z.; OLIVEIRA FILHO, F.; RIOS, D. As políticas públicas e o movimento da matemática moderna no Brasil In: Seminário Temático - O movimento da matemática moderna nas escolas do Brasil e de Portugal, 9., 2010, Juiz de Fora. Anais... Juiz de Fora: Universidade Federal de Juiz de Fora, 2010. p. 23-86.

COLMEZ, F. Lettre au Recteur Weil. Bulletin de l'APMEP, n. 282, p. 170-171, 1972. COLOMB, J.; DUMONT, M. Travail des comissions. Bulletin de l'APMEP, n. 271, p. 678-679, 1969.

COMMISSION D'ÉTUDE POUR L'ENSEIGNEMENT DES MATHÉMATIQUES. Comptes rendus des réunions des 11 février 1967, 10 avril 1967, 27 avril. 1967a. Archives nationales, C.A.C. Fontainebleau, 19870205/1. Digitalizado por Renaud d'Enfert.

COMMISSION D'ÉTUDE POUR L'ENSEIGNEMENT DES MATHÉMATIQUES. Rapport préliminaire de la comission ministérielle. Bulletin de l'APMEP, n. 258, p. 246-271, 1967b.

D’ENFERT, R. Matemáticas modernas e métodos ativos: as ambições reformadoras dos professores de matemáticas do secundário na Quarta República Francesa (19461958). História da Educação, ASPHE/FaE/UFPEL, v. 14, n. 32, p. 7-30, 2010.

D'ENFERT, R.; GISPERT, H. Une réforme à l'épreuve des réalités: le cas des "mathématiques modernes" en France, au tournant des années 1970. Capítulo da obra coletiva saída do COLLOQUE L'ÉTAT ET L'ÉDUCATION, 1808-2008, Paris, 2008. Paris: 2010. Disponível em: <http://halshs.archives-ouvertes.fr/halshs-00536328_v1/>. Acesso em: 25 maio 2011.

FORT ET DEHAME. Mesures. In: INSTITUT PÉDAGOGIQUE NATIONAL - IPN. Mathématiques en 6e: expérimentation et nouveaux programmes. Paris: IPN, 1969. 
GLAYMANN, M. Les relations. In: INSTITUT PÉDAGOGIQUE NATIONAL IPN. Mathématiques en 6e: expérimentation et nouveaux programmes. Paris: IPN, 1969.

GROUPES DE BORDEAUX ET DE TALENCE. Comptes Rendus Regionaux. In: INSTITUT PÉDAGOGIQUE NATIONAL - IPN. Mathématiques en 5e: expérimentations et nouveaux programmes. Paris: IPN, 1970. p. 7-9.

INTERNATIONAL COMISSION OF MATHEMATICAL INSTRUCTION - ICMI. New trends in mathematics teaching. Paris: UNESCO, 1966.

LEGRAND, L. Avant-propos. In: INRDP. Mathématiques en 3e: bilan d'une expérimentation dans le $1^{\text {er }}$ cycle. Paris: INRDP, 1972.

MATOS, J. M.; VALENTE, W. R. Estudos comparativos sobre a reforma da Matemática Moderna. In: MATOS, J. M.; VALENTE, W. R. (Org.). A reforma da matemática moderna em contextos ibero-americanos. Lisboa: UIED, 2010. p. 1-7.

PROST, A. Histoire de l'enseignement et de l'éducation en France: l'école et la famille dans une societé en mutation (depuis 1930). Paris: Perrin, 2004. v. 4.

REVUZ, A. Une année d'expérience dans des classes de $6^{\mathrm{e}}$. In: INSTITUT PÉDAGOGIQUE NATIONAL. Mathématiques en 6e: expérimentation et nouveaux programmes. Paris: 1969.

REVUZ, A. Avant-propos. In: INRDP. Mathématiques en 3e: bilan d'une expérimentation dans le $1^{\text {er }}$ cycle. Paris: INRDP, 1972.

REVUZ, A. Lichnérowicz et la réforme des mathématiques. Gazette des Mathématiciens, SMF, n. 82, p. 90-92, 1999.

RIBEIRO, M. L. S. O colégio vocacional "Oswaldo Aranha" de São Paulo. In: GARCIA, W. E. (Org.). Inovação educacional no Brasil. São Paulo: Cortez, 1980. p. 123-149.

WALUSINSKI, G. L'actualité: deux méthodes. Bulletin de l'APMEP, n. 251, p. 144-146, 1966. 
WALUSINSKI, G. Des comissions et des réformes. Bulletin de l'APMEP, n. 257, p. 138-144, 1967.

WALUSINSKI, G. L'appareillage. Bulletin de l'APMEP, n. 269-70, p. 269-272, 1969. WALUSINSKI, G. L'instructive histoire d'un échec: les mathématiques modernes (1955-1972). Paris: APMEP, 1986. Disponível em: <http://www.apmep. asso.fr/L-instructive-histoire-d-un-echec >. Acesso em: 25 maio 2011.

Recebido: 19/05/2010

Received: 05/19/2010

Aprovado: 21/10/2010

Approved: 10/21/2010 